\title{
The WMU Journal of Maritime Affairs celebrates its 20th anniversary
}

\author{
Jens-Uwe Schröder-Hinrichs ${ }^{1}$
}

Published online: 14 September 2021

(c) World Maritime University 2021

It is 20 years ago that the first issue of the WMU Journal of Maritime Affairs (JOMA) was published-an opportunity to look back at the beginning of the journal-to consider its achievements and to chart the future course that the journal should steer in its future development.

JOMA was established at a time when the World Maritime University (WMU) underwent a significant change of its academic profile and nature. Initially, when the university was founded by the International Maritime Organization (IMO), the capacity building mandate of WMU was realized primarily through the teaching programs only. Fifteen years later, the university had developed up to a level where research-related aspects became a top priority for further enhancing the academic profile of WMU. The first editorial in JOMA, written by then-WMU President Karl Laubstein (2002), referred to the introduction of a doctoral program at WMU and an expanded research focus. The editorial also referred to WMU's special mandate and the role the University plays internationally in relation to global capacity building in furtherance of the objectives of the parent body of WMU: that is, IMO, a specialized agency of the United Nations. It is within this context that JOMA was set up as a contribution by WMU to the wider maritime community-administrations, industry, as well as education and research — with the objective of stimulating critical discussions on contemporary maritime issues. Contrary to today's academic journal scene, there were hardly any maritime journals at the time JOMA was established. It was felt that WMU, as a result of its special nature, has the capability of bringing together a wide variety of researchers and professionals as authors so as to generate the content needed for such a journal at the right academic level. Twenty years later, we can say that the JOMA succeeded and met the objectives.

The beginning of the Journal was quite simple. JOMA was published twice a year with five to six manuscripts per issue. The founding editor, Professor Günther Zade, first Vice-Rector of WMU for almost 20 years, approached most of the authors personally to invite them to write for the journal. This practice was continued until

Jens-Uwe Schröder-Hinrichs

jus@wmu.se

1 World Maritime University, Malmö, Sweden 
2006, when Günther Zade passed away. Karl Laubstein had the confidence in a young team of WMU faculty members to continue developing the journal, and this is how I became an editor of the journal, supported by my colleagues Max Mejia and Pierre Cariou.

The new editorial team developed an ambitious vision for the journal, and one of the first priorities was to ensure that the journal would find its place among other respectable journals in its field. In 2006, JOMA was already well-regarded; we focused on ensuring that we would no longer rely on invited manuscripts, but instead develop the journal into a preferred outlet for publications in an author community with strong interest in maritime topics.

The Journal was produced in-house until 2010. This meant that all the editorial corrections and suggestions were done at WMU and with the help of faculty support staff. For the layout, an external consultant, Peter Larsson, was employed who helped us not only with the journal, but also with a number of other publications that WMU produced at that time. In due course, we managed to even host electronic versions of the journal on an independent online platform. However, it became clear that it would need a more professional foundation if the journal wanted to explore and materialize its full potential. We were very fortunate to receive an expression of interest from Springer to help us grow our academic publications and make them available to a global audience through their professional publishing network. This was a big step that lifted JOMA to a completely different level and I would like to use this opportunity and thank Brigitte Reschke and Andreas Vogel for all their help, encouragement, and support over the years. Another milestone of further development was the cooperation with the International Association of Maritime Universities (IAMU) who selected JOMA for a publishing partnership in 2014 and established the IAMU Section in the journal where manuscripts related to "Maritime Education and Training" (MET) are submitted for publication.

I handed over my editorship to my colleague Aykut Ölcer in 2017 from whom the current editor, Dong-Wook Song, took over in 2019. They both grew the journal substantially from two issues we published in 2016 to four issues with almost 600 pages in 2019. JOMA is covered by analytical platforms, and the indicators provided by these platforms in terms of citations and impact of the Journal are very promising as was confirmed by the 2020 review paper by Sahoo and Schönborn (2020). I am therefore very confident for further academic presence of JOMA in the domain of maritime affairs over the years to come.

From this chronological account of the Journal's early years, I would like to move on to review the topics covered over the years and the contributions we have made tothe discipline of maritime affairs. It will not be possible to discuss all the different interesting manuscripts we have published during the last 20 years. However, it may be worthwhile to go back to the first issue from October 2002 in order to see how it all started. The first issue included six articles and two book reviews. The topics covered were highly relevant and still touch on important discussions which are still relevant to a certain extent even today. The issue started with an article by Harilaos Psaraftis (2002), regarding the approaches to be taken to increase ship safety, who was discussing the question of whether maritime safety policies should be more proactive or not. He did then critically make a point that maritime safety policies 
are usually not so much developed as a result of a proactive approach. At the time JOMA was initiated, accidents had quite a significant impact on the development of maritime safety policies and regulations. Psaraftis criticized that the response to accidents often involved mainly changes in design and technology and did not pay enough attention to the human factor. He also suggested that the focus in policy and regulation-making should be changed to preventive measures leading to a reduced accident probability. Member States of IMO have come a long way during the last 20 years, but the message of this article should still remind us about the importance of making proactive safety policies.

This also applies to the second manuscript of the first issue written by Jaime Veiga (2002) about safety culture in shipping, a relatively new approach at the time. Veiga saw positive indicators of a beginning to implement such mindset into the shipping industry as a result of STCW 1995 and the ISM Code. However, he also noted that the shipping industry as a whole needed to change significantly to adopt this approach. We have published many manuscripts over the years reviewing maritime safety regulations, the human element and safety culture in shipping. Out of these, the editorial by the former IMO Secretary General William O'Neil (2003) should be mentioned who focused on the human element in shipping and highlighted the role that member States play through implementation and enforcement. This was echoed in the 2004 editorial by former IMO Secretary General Efthimios Mitropoulos (2004), who introduced the IMO member State auditing scheme as a tool to systematically stimulate improvements in maritime safety and marine environmental protection through close internal cooperation. The human element in shipping is a key factor in maritime safety that requires further discussion which continues to result in interesting articles published in this journal.

The first issue of JOMA also included two articles about oil spills—one from a technical perspective of oil spill response operations by Ian C. White (2002), Managing Director of International Tanker Owners Pollution Federation-the other one focusing on oil spill compensation written by Måns Jacobsson (2002), Director of the International Oil Pollution Compensation Funds. These articles were published almost 2 years after the Erika oil spill of the French coast and only a few weeks before the Prestige oil spill in the Bay of Biscay. Both accidents initiated major discussions about tanker safety, double hull ship design, and places of refuge. They also resulted in significant changes in legislation, as highlighted by Uwe Jenisch (2004) in his article where he analyzed the follow-up to Erika and Prestige in the European Union, with, among others, the establishment of the European Maritime Safety Agency. The focus on oil spills has fortunately changed as result of the further reduction of tanker accidents over the years. However, JOMA has always paid attention to issues related to marine environmental protection and shipping as indicated by Psaraftis and Kontovas (2009) who focused on $\mathrm{CO}_{2}$ emissions in the world commercial fleet and the work of Notteboom (2011) discussing the implications of low sulfur requirements for roro shipping in Northern Europe.

The first issue also included a manuscript written by Horst Hecht (2002) about ECDIS in shipping. While JOMA has not become a journal with a strong technology component, it included a number of maritime simulation-related articles, especially in its MET section. It is also hoped that the current discussion about 
autonomous ships may result in a number of thought-provoking manuscripts that will find their way into the journal's space.

The last article of the first JOMA issue focused on multimodal transport and covered specifically issues related to liability. It was written by Malcom Clarke (2002). It is one of the many articles published in relation to maritime law and policy over the years where leading authors shared their views on contemporary maritime legal issues.

Thus, the contents of the first issue of twenty years ago was representative of to the topics that have remained as important and topical ever since. However, this brief review and reflection is also very much related to the question of what maritime affairs are in general. The term maritime affairs is not an original scientific discipline. Like safety sciences, it is an area that draws from a variety of disciplines, such as engineering, law, policy, psychology, education, economics, social sciences, physics, management, geography, and biology. The term is the headline under which research and publications are undertaken within the maritime sector, an industry that provides essential services to our globalized world. The important role that shipping plays in global supply chains became noticeable during recent months of the COVID pandemic. I also think that the blockage of the Suez Canal a few months ago was quite a significant reminder that our daily life is very much dependent upon a functioning shipping industry. Unfortunately, while the importance of shipping might not be accorded its deserved recognition, nor the work of seafarers as key workers valued at the level that it deserves, we will continue to publish the WMU Journal of Maritime Affairs in order to play our part by providing more visibility and recognition of the global shipping sectorand academic works conducted within maritime affairs.

Looking forward to the next 20 years of JOMA

Jens-Uwe Schröder-Hinrichs

Consulting Editor

\section{References}

Clarke M (2002) Multimodal transport in the New Millennium. WMU J Marit Aff 1(1):71-84

Hecht H (2002) Potential and benefits of electronic charts to maritime administration. WMU J Marit Aff 1(1):33-45

Jacobsson M (2002) The international regime of compensation for oil pollution damage and the policy of the international oil pollution compensation funds as to the admissibility of claims. WMU J Marit Aff 1(1):59-69

Jenisch U (2004) EU maritime transport - maritime policy, legislation and administration. WMU J Marit Aff 3(1):67-83

Laubstein K (2002) Editorial - WMU Journal of Maritime Affairs. WMU J Marit Aff 1(1):1

Mitropoulos E (2004) IMO: raising to new challenges. WMU J Marit Aff 3(4):107-110

Notteboom T (2011) The impact of low sulphur fuel requirements in shipping on the competitiveness of RoRo shipping in Northern Europe. WMU J Marit Aff 10(1):63-95

O’Neil W (2003) Editorial - the human element in shipping. WMU J Marit Aff 2(2):95-97

Psaraftis H (2002) Maritime safety: to be or not to be proactive. WMU J Marit Aff 1(1):3-16

Psaraftis $\mathrm{H}$, Kontovas $\mathrm{C}$ (2009) $\mathrm{CO}_{2}$ emission statistics for the world commercial fleet. WMU J Marit Aff 8(1):1-25 
Sahoo S, Schönborn A (2020) A bibliometric overview of WMU Journal of Maritime Affairs since its Inception in 2002. WMU J Marit Aff 19(1):5-25

Veiga J (2002) Safety culture in shipping. WMU J Marit Aff 1(1):17-31

White I (2002) The realities of combating major tanker spills. WMU J Marit Aff 1(1):47-58

Publisher's note Springer Nature remains neutral with regard to jurisdictional claims in published maps and institutional affiliations. 